\title{
The Influence of Morinda citrifolia (Noni) Fruit Juice on Collagen Deposition in the Skin: A Minireview
}

\author{
Brett J. West \\ Research and Development, Morinda Inc., American Fork, UT, USA \\ Email: brett_west@morinda.com
}

How to cite this paper: West, B.J. (2018) The Influence of Morinda citrifolia (Noni) Fruit Juice on Collagen Deposition in the Skin: A Minireview. Journal of Biosciences and Medicines, 6, 1-10. https://doi.org/10.4236/jbm.2018.69001

Received: August 7, 2018

Accepted: September 2, 2018

Published: September 5, 2018

Copyright $\odot 2018$ by author and Scientific Research Publishing Inc. This work is licensed under the Creative Commons Attribution International License (CC BY 4.0).

http://creativecommons.org/licenses/by/4.0/

\section{(c) (i) Open Access}

\begin{abstract}
The fruit of Morinda citrifolia, commonly known as noni, has an extensive history of use as a food and medicine throughout the tropics. Among its many uses, noni was believed to promote skin health. In vivo wound healing studies reveal that noni fruit juice ingestion increases collagen production and deposition via increased expression of extracellular matrix protein genes. Noni juice also appears to promote fibroblast proliferation. In vitro studies indicate that noni juice also protects fibroblasts via activation of the transcription factor Nrf2 and protects extracellular matrix collagen by inhibiting matrix metalloproteinases. In vitro and in vivo study findings are corroborated by a clinical trial where hospitalization times were reduced, and wound granulation quality was improved in pediatric burn patients. The findings of other human studies also indicate that noni juice has the potential to protect skin collagen. These include reduced plasma reactive oxygen species in cigarette smokers, lowered skin glycation levels in overweight and obese adults, as well as reduced skin glycation levels among noni juice consumers within the general population. These in vitro, in vivo and human studies reveal that there are multiple mechanisms of action through which noni juice promotes collagen synthesis and inhibits collagen degradation. The procollagen properties of noni juice aid wound healing, increase skin elasticity, and improve the overall appearance of the skin.
\end{abstract}

\section{Keywords}

Morinda citrifolia, Noni, Collagen, Fibroblast, Matrix Metalloproteinases

\section{Introduction}

Dietary factors may have a significant impact on skin health. It is well estab- 
lished that proper nutrition is important for maintaining healthy skin and for adequate wound healing. Perhaps, the best-known example of this is vitamin C's vital role in collagen synthesis. A chronic deficiency of this vitamin results in scurvy with its characteristic symptoms of bleeding gums and susceptibility to bruising. These symptoms are due to inadequate collagen synthesis by fibroblasts [1]. Other dietary factors, such as phytochemical constituents of plants, may also have an impact on skin health and biomechanical properties [2]. Some of these phytochemicals may exert their positive effects on the skin by influencing collagen production [3].

Morinda citrifolia is a tree that grows widely across tropical regions of the world. Its common names are noni and Indian mulberry. It is a small to medium sized tree with dark green, glossy, and elliptical leaves. The fruit, which grows year-round, is an ovoid syncarp that changes from green to pale yellow, then finally to white, during ripening and senescence. The leaves and fruit, as well as other plant parts, had significant roles in Pacific, South Asian, Southeast Asian, and Caribbean material medica [4]. In fact, noni is reported to be the most important and widely used Polynesian medicinal plant prior to the European era [5]. Various parts of the plant were used by local healers to treat inflammation, osteoarthritis, rheumatism, backache, joint problems, abscesses, angina, diabetes, ranula, abdominal fibromas, scorpionfish stings, hemorrhoids, skin allergies, burns, and warts [6] [7] [8]. Today, noni fruit juice is produced commercially as a dietary supplement that is used to promote overall health and for use in skin care products. Many of the traditional perceptions of noni seem to be validated by the results of human clinicals trials, especially those involving noni fruit juice. Among the recorded effects of noni juice ingestion are the protection of DNA, control of tobacco-smoke induced blood lipid and homocysteine elevation, control of systemic inflammation, improvement of joint health, increased physical endurance, increased immune activity, inhibition of advanced glycation end product (AGE) formation, weight management, maintenance of bone health, normalization of blood pressure, and improved gum health [9].

Some Pacific Islanders believe that improved skin health is one of the benefits of drinking noni juice [10]. This is also an opinion held among European noni juice consumers [11]. As type 1 collagen is a major structural component of the skin, these benefits may be related to noni's ability to influence collagen synthesis and deposition. This review discusses the findings of in vitro and in vivo studies, as well as human studies, that help us better understand the potential effects of noni juice ingestion on skin collagen.

\section{In Vivo Studies}

Ingestion of noni fruit juice appears to promote the synthesis of collagen in the skin. This effect has been observed directly in vivo, such as in a 10-day feeding study with diabetic Sprague-Dawley rats [12]. In this study, animals with skin wounds were divided into three groups. Those in the first group were non-diabetic 
controls. The second and third groups included diabetic rats, with those in the third group receiving noni juice in their drinking water. All animals were monitored for wound closure rates. Histological and biochemical analyses of wound granulation tissues were also performed. The average wound closure rate was significantly greater among the animals in the noni juice group, when compared to the diabetic controls. A trend for accelerated wound healing was also observed when the noni-fed rats were compared to the non-diabetic controls. Histological analyses revealed that both the non-diabetic and diabetic control animals, when compared to the noni juice group, had less collagen formation and poorer cross-linking and directional organization within collagen fibers. The hydroxyproline content (mean \pm standard deviation), a biochemical marker for collagen, was greater in the noni juice group $(92.16 \pm 4.02 \mathrm{mg} / \mathrm{g})$ than in the non-diabetic controls $(66.00 \pm 2.40)$ or in the diabetic controls $(52.66 \pm 2.87)$. Due to the potential for noni juice to influence blood sugar levels, the improved wound healing in diabetic animals was somewhat anticipated. But the increased collagen production in noni juice-fed animals, beyond that experienced by the non-diabetic control group, demonstrates that the mechanisms of action go beyond mitigating the effects of elevated blood glucose.

The procollagen properties of noni juice were also observed in C57/BL6 mice [13]. In these mice, ingestion of noni juice accelerated the healing of lesions from leishmaniasis. But among the uninfected reference groups in this study, the noni juice fed animals also had greater expression of extracellular matrix protein genes (collagen I and III, laminin, and fibronectin) than the control mice. In fact, expression of collagen I and III was more than doubled by noni juice.

Noni fruit juice also appears to promote the proliferation of fibroblasts, the cells responsible for collagen synthesis. Increased fibroblast populations were evident in tooth excision wounds where a noni fruit juice-based gel had been applied for three days [14]. The average fibroblast count was approximately $21 \%$ greater than that of the control group.

The ability of noni to increase collagen synthesis is not uncontrolled, however. In the case of thioacetamide-induced liver injury, which leads to hepatic fibrosis, noni juice ingestion reduced average collagen concentration in the livers of Wistar rats [15]. Certainly, this reduction is associated with its liver protection and anti-inflammatory properties. But the authors of this study also reported that noni juice upregulated gene expression of matrix metalloproteinase inhibitors, TIMP-1 and TIMP-3, while suppressing the activity of two specific matrix metalloproteinases, MMP-2 and MMP-9. Additionally, an ethanol extract from noni fruit puree inhibited MMP-9 release from human monocytes in vitro [16]. Further, the feeding of noni fruit juice for 6 weeks reduced hepatic MMP-9 activity in high-fat diet hamsters [17]. These MMPs degrade collagen, which then signals compensatory mechanisms. Therefore, noni juice appears to protect hepatic extracellular matrix from aggressive matrix metalloproteinases (MMP) action which, in turn, may prevent abnormal collage synthesis that results in fibro- 
sis [18].

Aucubin and geniposidic acid are iridoid glycosides with chemical structures similar to those of two major phytochemical constituents of noni, deacetylasperulosidic acid and asperulosidic acid [19]. Ingestion of these two iridoids stimulates increased skin collagen synthesis in Wistar/ST rats, especially under conditions that accompany aging [20]. Geniposidic acid also increased stratum corneum turnover of rats by $23 \%$, leading to improved renewal of the outer layer of the skin [21]. These findings may provide some insight into which active principles in noni fruit juice improve the quality of the skin, with deacetylasperulosidic acid and asperulosidic acid likely playing leading roles.

\section{In Vitro Mechanistic Studies}

An ethanol extract of noni fruit exhibited a collagen-producing effect in vitro. The extract was found to up-regulate the synthesis of procollagen type 1 C-terminal peptide, a precursor of type 1 collagen, and glycosaminoglycans in normal human fibroblasts [22].

Juice from ripe noni fruit activated nuclear factor erythroid 2-related factor 2 (Nrf2) in microvascular endothelial cells [23]. Nrf2 helps maintain the normal function of fibroblasts and protects them against reactive oxygen species-mediated damage, such as that occurring from UVA light exposure [24]. Thus, Nrf2 activation by noni fruit juice can help maintain healthy collagen synthesis and deposition in the skin by protecting fibroblasts.

The influence of noni juice on MMP-2 and MMP-9 expressions and activities were discussed earlier. But even more relevant is the effect of noni juice on MMP-1. MMP-1 has the greatest effect on type 1 collagen hydrolysis. MMP-1 inhibitors may support healthy skin structure by limiting the degradation of the skin's collagen-extracellular matrix (ECM). An ethanol extract of noni seeds reportedly inhibited MMP-1 secretion from UVA-irradiated normal human dermal fibroblasts [25]. Using bioassay guided fractionation and isolation, a lignan, 3,3-bisdemethylpinoresinol, was found to be responsible for this activity. This lignan has also been identified in the fruit, along with other biologically active lignans [26] [27].

Other phytochemicals in noni fruit also contribute to the protection of the ECM. Scopoletin inhibits collagenase and elastase activities in vitro [28] [29]. Iridoids inhibit nuclear factor- $\mathrm{k} \beta$ (NF-k $\beta)$, which is one of the mechanisms by which they exert their biological effects [30]. NF- $k \beta$ activates collagenases, such as MMP-1 [31]. In fact, direct inhibition of MMP-1 has been reported for aucubin, which is structurally similar to the iridoids in noni fruit [32]. Also, $\mathrm{NF}-\mathrm{k} \beta$ activation decreases type 1 collagen synthesis by downregulating expression of the alpha-1(I) collagen gene [33]. Thus, the inhibition of NF-k $\beta$ helps both type 1 collagen synthesis as well as prevents its degradation. Asperulosidic acid, the second most abundant iridoid in noni fruit, as well as 6-O-( $\beta$-D-glucopyranosyl)-1-O-octanoyl- $\beta$-D-glucopyranose, a saccharide fatty 
acid ester also found in noni fruit, inhibit AP-1 activity in mouse epidermal cells [34]. AP-1 is a transcription factor that activates collagenase expression. As such, inhibition of AP-1 represents another ECM protective mechanism potentially enhanced by noni fruit juice ingestion.

\section{Human Studies}

The use of topical formulations with noni fruit juice improved the viscoelastic properties of the skin of adult volunteers. Daily application of a noni-based skin care regiment improved average skin firmness/elasticity by up to $42.4 \%$ in 49 women, ages 38 to 55 years [35]. In another human trial, a cream containing an ethanol extract of noni was applied to the face of 22 adult women in the morning and evening for four weeks [36]. Daily application of the extract significantly reduced the severity of wrinkles under the eyes. When this extract was evaluated in vitro, it decreased MMP-1 activity in human epidermal cells. Skin firmness and elasticity are directly related to dermal collagen and elastin networks [37]. Thus, improved elasticity of the skin after using the topical noni-based treatments suggest that the active procollagen substances in noni fruit may be absorbed through the skin.

The results of clinical trials involving pediatric burn patients, cigarette smokers, and overweight adults, as well as the results of a cross-sectional population study, provide more insight into the potential effect of noni juice ingestion on skin collagen deposition. An open-label prospective intervention study of noni juice was conducted with 30 pediatric patients (ages 2 - 9 yr.; $40 \%$ female, $60 \%$ male) who had been admitted to the Burn Service of Dr. Mario Ortiz Suarez Children's Hospital in Santa Cruz, Bolivia (Dr. Juan Carlos Jarandilla Rueda, unpublished report, January 2014). The purpose of this study was to evaluate the effect of noni juice, an approved safe food, on clinical outcomes and hospitalization time while patients concurrently received standard medical care. Informed consent was obtained from the families of the patients prior to being given noni juice. The intervention included drinking 1 fluid ounce $(30 \mathrm{~mL})$ of a noni juice product (provided by Morinda, Inc. American Fork, Utah, USA) two times per day for a maximum of 30 days. Clinical observations were recorded by the nursing staff and Burn Service resident physician. Patients who received noni juice experienced improved mood, faster development of granulation tissue, as well improved granulation quality, and decreased hospitalization time. These observations appear to corroborate the findings of the in vivo studies.

Noni juice is known to possess significant antioxidant activity. Its efficacy was demonstrated in 285 tobacco users who smoked more than 20 cigarettes per day. When compared to a placebo group, smokers who drank 29.5 to $118 \mathrm{~mL}$ of noni juice from Tahiti (TNJ) for 30 days experienced significant declines in plasma superoxide anion radicals (SAR) and lipid hydroperoxide (LOOH) levels [38]. Further, lipid peroxide and malondialdehyde DNA adducts were reduced by $44.6 \%-57.4 \%$ in smokers who drank TNJ for one month. Those consuming a 
placebo, however, had no change in DNA adduct levels [39]. It is notable that the free radical and DNA adduct declines occurred in those who continued to smoke heavily. Thus, the antioxidant action of noni juice is significant even under conditions of extreme oxidative stress.

The antioxidant properties of noni juice are relevant to skin health since the ECM may be damaged by reactive oxygen species (ROS), UV light and subsequent oxidative stress. The damage involves multiple pathways including the activation of AP-1 by ROS (i.e. SAR and LOOH), which then increases the expression of MMPs that degrade collagen and damage the dermis [40]. This is one reason why cigarette smokers are known for poor skin quality and increased wrinkling [41]. However, noni juice increases superoxide dismutase and catalase activity [42]. It is through these antioxidant enzymes that noni juice is able to lower SAR and $\mathrm{LOOH}$ and thereby limit collagen fragmentation in the skin.

The antiglycation properties of noni fruit juice were demonstrated in a two-month intervention study with overweight adults and in a cross-sectional population study [43]. In these studies, advanced glycation end product (AGE) accumulation within the body was determined through skin autofluorescence [44]. In the two-month intervention study, changes to skin autofluorescence were measured in 34 overweight or obese adults with impaired fasting glucose and elevated blood pressure (prehypertension or grade 1 hypertension). The average initial skin autofluorescence of this group was typical of a healthy 44-year-old adult. But this group's average actual age was 40 , four years younger than its AGE associated age (ASA). By the end of the trial, noni juice supplementation reduced the average ASA to 39 years. This represents a significant decrease in the AGE levels of these volunteers.

The cross-sectional population study included 3913 Japanese adults from 10 cities. A questionnaire was used to collect demographic data and information on daily noni juice ingestion rates. Skin autofluorescence was used to measure AGE burden in 2790 noni juice consumers and 1123 controls (those who did not drink noni juice). Regression analysis revealed that drinking noni juice is associated with lower AGE levels and that the average ASA was 2.07 years less among noni juice consumers than in the general population. This antiglycation activity is helpful in maintaining a healthy ECM in the skin since AGEs inhibit collagen deposition by stimulating fibroblast apoptosis [45]. Reduced dermis thickness, with shortened, thinned, and disorganized collagen fibrils, is associated with higher AGE levels in the skin [46]. The influence of AGEs on skin properties is also evident in that fact that skin elasticity is reduced while skin autofluorescence increases with increasing age [47]. As such, AGEs have a negative impact on skin structure, collagen organization, and skin elasticity. Such negative effects may be mitigated by drinking noni juice.

\section{Conclusion}

Noni fruit juice provides many health benefits. These include the maintenance or improvement of skin health. In vitro, in vivo and human studies reveal that 
multiple mechanisms of action are likely responsible for these benefits. Noni juice contains phytochemicals that have notable antioxidant activity, promote collagen synthesis and inhibit collagen degradation. The combination of these effects leads to improved wound healing, skin firmness and elasticity, and overall appearance.

\section{Conflicts of Interest}

The author declares no conflicts of interest regarding the publication of this paper.

\section{References}

[1] Pullar, J.M., Carr, A.C. and Vissers, M.C.M. (2017) The Roles of Vitamin C in Skin Health. Nutrients, 9, 866.

[2] Perez-Sanchez, A., Barrajon-Catalan, E., Herranz-Lopez, M. and Micol, V. (2018) Nutraceuticals for Skin Care: A Comprehensive Review of Human Clinical Studies. Nutrients, 10, 403. https://doi.org/10.3390/nu10040403

[3] Stipcevic, T., Piljac, J. and Vanden Berghe, D. (2006) Effect of Different Flavonoids on Collagen Synthesis in Human Fibroblasts. Plant Foods Human Nutrition, 61, 27-32. https://doi.org/10.1007/s11130-006-0006-8

[4] Morton, J. (1992) The Ocean-Going Noni, or Indian Mulberry (Morinda citrifolia, Rubiaceae) and Some of Its "Colorful” Relatives. Economic Botany, 46, 241-256. https://doi.org/10.1007/BF02866623

[5] Whistler, W.A. (1992) Polynesian Herbal Medicine. National Tropical Botanical Garden, Hong Kong.

[6] Petard, P. (1986) Quelques Plantes Utiles de Polynesie Francaise et Raau Tahiti. Editions Haere Po No Tahiti, Papeete.

[7] Brown, F.B.H. (1935) Flora of Southeastern Polynesia. III. Dicotyledons. Bishop Museum, Honolulu.

[8] Girardi, C., Butaud, J.F., Ollier, C., Ingert, N., Weniger, B., Raharivelomanana, P. and Moretti, C. (2015) Herbal Medicine in the Marquesas Islands. Journal of Ethnopharmacology, 161, 200-213. https://doi.org/10.1016/j.jep.2014.09.045

[9] West, B.J., Deng, S., Isami, F., Uwaya, A. and Jensen, C.J. (2018) The Potential Health Benefits of Noni Juice: A Review of Human Intervention Studies. Foods, 7, 58. https://doi.org/10.3390/foods7040058

[10] Pande, M., Naiker, M., Mills, G., Singh, N. and Voro, T. (2005) The Kura Files: Qualitative Social Survey. Pacific Health Surveillance and Response, 12, 85-93.

[11] Westendorf, J. and Mettlich, C. (2009) The Benefits of Noni Juice: An Epidemiological Evaluation in Europe. Journal of Medicinal Food Plants, 1, 64-79.

[12] Nayak, B.S., Isitor, G.N., Maxwell, A., Bhogadi, V. and Ramdath, D.D. (2007) Wound-Healing Activity of Morinda citrifolia Fruit Juice on Diabetes-Induced Rats. Journal of Wound Care, 16, 83-86. https://doi.org/10.12968/jowc.2007.16.2.27006

[13] Almeida-Souza, F., Cardoso, F.O., Souza, B.V., do Valle, T.Z., de Sá, J.C., Oliveira Idos, S., de Souza, C.S., Moragas Tellis, C.J., Chagas, M.S., Behrens, M.D., Abreu-Silva A.L. and Calabrese, K.S. (2016) Morinda citrifolia Linn. Reduces Parasite Load and Modulates Cytokines and Extracellular Matrix Proteins in C57BL/6 Mice Infected with Leishmania (Leishmania) amazonensis. PLoS Neglected Tropical Dis- 
eases, 10, e0004900. https://doi.org/10.1371/journal.pntd.0004900

[14] Khoswanto, C. (2010) Mengkudu (Morinda citrifolia Linn.) Gel Affect on Post-Extraction Fibroblast Acceleration. Dental Journal: Majalah Kedokteran Gigi, 43, 31-34. https://doi.org/10.20473/j.djmkg.v43.i1.p31-34

[15] Lin, Y.L., Lin, H.W., Chen, Y.C., Yang, D.J., Li, C.C. and Chang, Y.Y. (2017) Hepatoprotective Effects of Naturally Fermented Noni Juice against Thioacetamide-Induced Liver Fibrosis in Rats. Journal of the Chinese Medical Association, 80, 212-221. https://doi.org/10.1016/j.jcma.2016.10.014

[16] Basar, S., Uhlenhut, K., Högger, P., Schöne, F. and Westendorf, J. (2010) Analgesic and Antiinflammatory Activity of Morinda citrifolia L. (Noni) Fruit. Phytotherapy Research, 24, 38-42. https://doi.org/10.1002/ptr.2863

[17] Lin, Y.L., Chang, Y.Y., Yang, D.J., Tzang, B.S. and Chen, Y.C. (2013) Beneficial Effects of Noni (Morinda citrifolia L.) Juice on Livers of High-Fat Dietary Hamsters. Food Chemistry, 140, 31-38. https://doi.org/10.1016/j.foodchem.2013.02.035

[18] Duarte, S., Baber, J., Fujii, T. and Coito, A.J. (2015) Matrix Metalloproteinases in Liver Injury, Repair and Fibrosis. Matrix Biology, 44-46, 147-156.

https://doi.org/10.1016/j.matbio.2015.01.004

[19] Deng, S., West, B.J., Palu, A.K. and Jensen, C.J. (2011) Determination and Comparative Analysis of Major Iridoids in Different Parts and Cultivation Sources of $\mathrm{Mo}$ rinda citrifolia. Phytochemical Analysis, 22, 26-30. https://doi.org/10.1002/pca.1246

[20] Li, Y., Sato, T., Metori, K., Koike, K., Che, Q.M. and Takahashi, S. (1998) The Promoting Effects of Geniposidic Acid and Aucubin in Eucommia ulmoides Oliver Leaves on Collagen Synthesis. Biological \& Pharmaceutical Bulletin, 21, 1306-1310. https://doi.org/10.1248/bpb.21.1306

[21] Li, Y., Metori, K., Koike, K., Che, Q.M. and Takahashi, S. (1999) Improvement in the Turnover Rate of the Stratum Corneum in False Aged Model Rats by the Administration of Geniposidic Acid in Eucommia ulmoides Oliver Leaf. Biological \& Pharmaceutical Bulletin, 22, 582-585. https://doi.org/10.1248/bpb.22.582

[22] Kim, S.W., Jo, B.K., Jeong, J.H., Choi, S.U. and Hwang, Y.I. (2005) Induction of Extracellular Matrix Synthesis in Normal Human Fibroblasts by Anthraquinone Isolated from Morinda citrifolia (Noni) Fruit. Journal of Medicinal Food, 8, 552-555. https://doi.org/10.1089/jmf.2005.8.552

[23] Senger, D.R. and Cao, S. (2016) Diabetic Wound Healing and Activation of Nrf2 by Herbal Medicine. Journal of Nature and Science, 2, pii: e247.

[24] Gęgotek, A. and Skrzydlewska, E. (2015) The Role of Transcription Factor Nrf2 in Skin Cells Metabolism. Archives of Dermatological Research, 307, 385-396. https://doi.org/10.1007/s00403-015-1554-2

[25] Masuda, M., Murata, K., Naruto, S., Uwaya, A., Isami, F. and Matsuda, H. (2012) Matrix Metalloproteinase-1 Inhibitory Activities of Morinda citrifolia Seed Extract and Its Constituents in UVA-Irradiated Human Dermal Fibroblasts. Biological \& Pharmaceutical Bulletin, 35, 210-215. https://doi.org/10.1248/bpb.35.210

[26] Lin, C.F., Ni, C.L., Huang, Y.L., Sheu, S.J. and Chen, C.C. (2007) Lignans and Anthraquinones from the Fruits of Morinda citrifolia. Natural Product Research, 21, 1199-1204. https://doi.org/10.1080/14786410601132451

[27] Deng, S., Palu, A.K., West, B.J., Su, C.X., Zhou, B.N. and Jensen, J.C. (2007) Lipoxygenase Inhibitory Constituents of the Fruits of Noni (Morinda citrifolia) Collected in Tahiti. Journal of Natural Products, 70, 859-862.

https://doi.org/10.1021/np0605539 
[28] Bissonnette, E.Y., Tremblay, G.M., Turmel, V., Pirotte, B. and Reboud-Ravaux, M. (2009) Coumarinic Derivatives Show Anti-Inflammatory Effects on Alveolar Macrophages, But Their Anti-Elastase Activity Is Essential to Reduce Lung Inflammation in Vivo. International Immunopharmacology, 9, 49-54. https://doi.org/10.1016/j.intimp.2008.09.009

[29] Oshima, N., Narukawa, Y., Takeda, T. and Kiuchi, F. (2013) Collagenase Inhibitors from Viola yedoensis. Journal of Natural Medicines, 67, 240-245. https://doi.org/10.1007/s11418-012-0665-8

[30] West, B.J., Deng, S., Uwaya, A., Isami, F., Abe, Y., Yamagishi, S. and Jensen, C.J. (2016) Iridoids Are Natural Glycation Inhibitors. Glycoconjugate Journal, 33, 671-681. https://doi.org/10.1007/s10719-016-9695-x

[31] Vincenti, M.P. and Brinckerhoff, C.E. (2004) Transcriptional Regulation of Collagenase (MMP-1, MMP-13) Genes in Arthritis: Integration of Complex Signaling Pathways for the Recruitment of Gene-Specific Transcription Factors. Arthritis Research, 4, 157-164. https://doi.org/10.1186/ar401

[32] Ho, J.N., Lee, Y.H., Lee, Y.D., Jun, W.J., Kim, H.K., Hong, B.S., Shin, D.H. and Cho, H.Y. (2005) Inhibitory Effect of Aucubin Isolated from Eucommia ulmoides against UVB-Induced Matrix Metalloproteinase-1 Production in Human Skin Fibroblasts. Bioscience, Biotechnology, and Biochemistry, 69, 2227-2231. https://doi.org/10.1271/bbb.69.2227

[33] Rippe, R.A., Schrum, L.W., Stefanovic, B., Solís-Herruzo, J.A. and Brenner, D.A. (1999) NF-kappaB Inhibits Expression of the Alpha1(I) Collagen Gene. DNA and Cell Biology, 18, 751-761. https://doi.org/10.1089/104454999314890

[34] Liu, G., Bode, A., Ma, W.Y., Sang, S., Ho, C.T. and Dong, Z. (2001) Two Novel Glycosides from the Fruits of Morinda citrifolia (Noni) Inhibit AP-1 Transactivation and Cell Transformation in the Mouse Epidermal JB6 Cell Line. Cancer Research, 61, 5749-5756.

[35] West, B.J. and Sabin, R. (2012) Efficacy of a Morinda citrifolia Based Skin Care Regimen. Current Research Journal of Biological Science, 4, 310-314.

[36] Kim, S.H. and Jang, H.J. (2016) Study on the Bioactive Characteristics of Morinda citrifolia as a Cosmetic Raw Material. Journal of the Society of Cosmetic Scientists of Korea, 42, 183-193. https://doi.org/10.15230/SCSK.2016.42.2.183

[37] Bischoff, J.E., Arruda, E.M. and Grosh, K. (2000) Finite Element Modeling of Human Skin Using an Isotropic, Nonlinear Elastic Constitutive Model. Journal of Biomechanics, 33, 645-652. https://doi.org/10.1016/S0021-9290(00)00018-X

[38] Wang, M.Y., Lutfiyya, M.N., Weidenbacher-Hoper, V., Anderson, G., Su, C.X. and West, B.J. (2009) Antioxidant Activity of Noni Juice in Heavy Smokers. Chemistry Central Journal, 3, 13. https://doi.org/10.1186/1752-153X-3-13

[39] Wang, M.Y., Peng, L., Jensen, C.J., Deng, S. and West, B.J. (2013) Noni Juice Reduces Lipid Peroxidation-Derived DNA Adducts in Heavy Smokers. Food Science and Nutrition, 1, 141-149. https://doi.org/10.1002/fsn3.21

[40] Tu, Y. and Quan, T. (2016) Oxidative Stress and Human Skin Connective Tissue Aging. Cosmetics, 3, 28. https://doi.org/10.3390/cosmetics3030028

[41] Morita, A., Torii, K., Maeda, A. and Yamaguchi, Y. (2009) Molecular Basis of Tobacco Smoke-Induced Premature Skin Aging. Journal of Investigative Dermatology Symposium Proceedings, 14, 53-55. https://doi.org/10.1038/jidsymp.2009.13

[42] Ma, D.L., Chen, M., Su, C.X. and West, B.J. (2013) In Vivo Antioxidant Activity of Deacetylasperulosidic Acid in Noni. Journal of Analytical Methods in Chemistry, 2013, Article ID: 804504. https://doi.org/10.1155/2013/804504 
[43] West, B.J., Uwaya, A., Isami, F., Deng, S., Nakajima, S. and Jensen, C.J. (2014) Antiglycation Activity of Iridoids and Their Food Sources. International Journal of Food Science, 2014, Article ID: 276950. https://doi.org/10.1155/2014/276950

[44] Meerwaldt, R., Graaff, R., Oomen, P.H.N., Links, T.P., Jager, J.J., Alderson, N.L., Thorpe, S.R., Baynes, J.W., Gans, R.O.B. and Smit, A.J. (2004) Simple Non-Invasive Assessment of Advanced Glycation Endproduct Accumulation. Diabetologia, 47, 1324-1330. https://doi.org/10.1007/s00125-004-1451-2

[45] Alikhani, Z., Alikhani, M., Boyd, C.M., Nagao, K., Trackman, P.C. and Graves, D.T. (2005) Advanced Glycation End Products Enhance Expression of Pro-Apoptotic Genes and Stimulate Fibroblast Apoptosis through Cytoplasmic and Mitochondrial Pathways. The Journal of Biological Chemistry, 280, 12087-12095. https://doi.org/10.1074/jbc.M406313200

[46] Niu, Y., Cao, X., Song, F., Xie, T., Ji, X., Miao, M., Dong, J., Tian, M., Lin, Y. and Lu, S. (2012) Reduced Dermis Thickness and AGE Accumulation in Diabetic Abdominal Skin. The International Journal of Lower Extremity Wounds, 11, 224-230. https://doi.org/10.1177/1534734612457570

[47] Corstjens, H., Dicanio, D., Muizzuddin, N., Neven, A., Sparacio, R., Declercq, L. and Maes, D. (2008) Glycation Associated Skin Autofluorescence and Skin Elasticity Are Related to Chronological Age and Body Mass Index of Healthy Subjects. Experimental Gerontology, 43, 663-667. https://doi.org/10.1016/j.exger.2008.01.012 